\title{
Recombinant human soluble thrombomodulin improves mortality in patients with sepsis especially for severe coagulopathy: a retrospective study
}

\author{
Takahiro Kato $^{1 *}$ and Katsuhiko Matsuura ${ }^{2}$
}

\begin{abstract}
Background: Disseminated intravascular coagulation (DIC) is associated with high mortality in patients with sepsis. Several studies reporting that recombinant human soluble thrombomodulin (rhTM) reduced mortality in sepsis patients. This retrospective cohort study aimed to evaluate the efficacy of rhTM for patients with mild coagulopathy compared with those with severe coagulopathy.

Methods: We evaluated about 90-day mortality and SOFA score. SOFA score was also evaluated for the following components: respiratory, cardiovascular, hepatic, renal and coagulation.

Results: All 69 patients were diagnosed with sepsis, fulfilled Japanese Association for Acute Medicine criteria for DIC, and were treated with rhTM. Patients were assigned to either the mild coagulopathy group (did not fulfill the International Society on Thrombosis and Haemostasis overt DIC criteria) or the severe coagulopathy group (fulfilled overt DIC criteria). The 90-day mortality was significant lower in severe coagulopathy group than mild coagulopathy group $(P=0.029)$. Although the SOFA scores did not decrease in the mild coagulopathy group, SOFA scores decreased significantly in the severe coagulopathy group. Furthermore the respiratory component of the SOFA score significant decreased in severe coagulopathy group compared with mild coagulopathy group.
\end{abstract}

Conclusions: rhTM administration may reduce mortality by improving organ dysfunction especially for respiratory in septic patients with severe coagulopathy.

Keywords: Thrombomodulin, Sepsis, Disseminated intravascular coagulation, Severe coagulopathy

\section{Background}

Sepsis and septic shock remain the most common cause of death in critically ill patients [1], and new therapeutic approaches are urgently needed. Ideal management of sepsis and septic shock remains controversial. Current evidence suggests that compliance with the Surviving Sepsis Campaign (SSC) guidelines is associated with decreased mortality [2-4]. Furthermore, it has been reported recently that early lactate clearance has a lower mortality risk than early goal-directed therapy [5].

\footnotetext{
* Correspondence: takkato1@aichi-med-u.ac.jp

1Departments of Pharmacy, Aichi Medical University, 1 -1 Yazakokarimata,

Nagakute, Aichi 480-1195, Japan

Full list of author information is available at the end of the article
}

Disseminated intravascular coagulation (DIC) is associated with high mortality in patients with sepsis [6]. Excessive coagulation activation, inhibition of fibrinolysis, and consumption of coagulation inhibitors lead to a hypercoagulable state, resulting in fibrin deposition in microvessels and inflammatory reactions [7]. Current management of DIC is primarily focused on treating any associated underlying medical condition, although use of supplemental clotting factors or platelets, or anticoagulant therapy may occasionally be required [8]. In particular, therapeutic intervention directly against coagulation

(c) The Author(s). 2018 Open Access This article is distributed under the terms of the Creative Commons Attribution 4.0 International License (http://creativecommons.org/licenses/by/4.0/), which permits unrestricted use, distribution, and 
and inflammation for DIC associated with sepsis is effective $[9,10]$, and it is generally accepted that early, aggressive treatment of the underlying disease is important. The revised Japanese Association for Acute Medicine (JAAM) criteria allows diagnosis of DIC in the earlier phase of disease than the overt DIC criteria published by the International Society on Thrombosis and Haemostasis (ISTH) [11].

Recombinant human soluble thrombomodulin (rhTM) is the only agent for the treatment of DIC [12]. rhTM was approved in 2008 and has been used clinically for DIC treatment in Japan. Several animal studies have demonstrated a reduction in mortality with the administration of rhTM in sepsis models [13]. Moreover, rhTM prevents endotoxin-induced lung injury in rats by leukocyte activation [14]. Multicenter retrospective study and meta-analysis have shown that rhTM improves mortality in sepsis patients $[15,16]$. Yamakawa et al. shown that rhTM improves coagulopathy and decreases SOFA score compared with control group in patients with sepsis [17].

We hypothesized that mortality would be improved after treatment with rhTM in septic patients especially for mild coagulopathy. Therefore, the purpose of this study was to evaluate the efficacy of rhTM for patients with mild coagulopathy compared with those with severe coagulopathy.

\section{Methods}

\section{Patients and study design}

This was a retrospective cohort study. All patients were admitted to Aichi Medical University Hospital intensive care unit (ICU) between May 2008 and and December 2014. Although the criteria for ICU admission were not standardized, all patients included in this study were diagnosed with sepsis what is according to SEPSIS-3 [18] and DIC diagnosed by JAAM criteria (Score $\geq 4$ ) [11] (Table 1), and were treated with rhTM. rhTM doses were $0.06 \mathrm{mg} / \mathrm{kg} /$ day (or $0.02 \mathrm{mg} / \mathrm{kg} /$ day for patients who required renal replacement therapy for acute kidney injury [AKI]); rhTM was administered for 30 min once daily. All patients were principally treated according to the SSC guidelines [19]. The exclusion criteria were: acute pancreatitis, burns, treatment with danaparoid sodium at the start of treatment, treatment with cyclosporine or tacrolimus until sepsis diagnosis, age $\leq 15$ years, and those not diagnosed with DIC due to a lack of laboratory data. A flow diagram of patient inclusion is shown in Fig. 1. The study protocol was reviewed and approved by an institutional review board. Informed consent was not required because blood samples were taken as part of the routine patient care for clinical laboratory testing, but the highest standard of privacy policy was applied.

\section{Data collection}

Relevant clinical background, medication history, and laboratory data of all patients were collected at appropriate times during the treatment for sepsis. We collected the patients' demographic and laboratory test data, including age, sex, clinical outcome (mortality at 90 days), shock (hypotension not reversed with fluid resuscitation) , presence of AKI as defined by the AKI network [20], acute physiologic and chronic health evaluation II

Table 1 JAAM criteria [11] and ISTH overt DIC criteria [22]

\begin{tabular}{|c|c|c|c|c|c|}
\hline & JAAM & & ISTH & & \\
\hline Score & 1 & 3 & 1 & 2 & 3 \\
\hline SIRS & $\geq 3$ items & & & & \\
\hline Platelet Count $\left(10^{3} / \mathrm{mL}\right)$ & $\begin{array}{l}\geq 80 \text { and }<120 \text {, or }>30 \% \text { decrease within } \\
24 \mathrm{~h}\end{array}$ & $\begin{array}{l}<80 \text { or } 50 \% \text { decrease within } \\
24 \mathrm{~h}\end{array}$ & $<100$ & $<50$ & \\
\hline $\mathrm{FDP}(\mu \mathrm{g} / \mathrm{mL})$ & $\geq 10$ and $<25$ & $\geq 25$ & & $\begin{array}{l}\geq 10 \text { and }<25 \\
\text { (Moderate } \\
\text { increase) }\end{array}$ & $\begin{array}{l}\geq 25 \\
\text { (Strong } \\
\text { increase) }\end{array}$ \\
\hline PT Ratio & $\geq 1.2$ & & & & \\
\hline $\begin{array}{l}\text { Prolonged prothrombin time } \\
\text { (sec) }\end{array}$ & & & $\begin{array}{l}3<,< \\
6\end{array}$ & $6<$ & \\
\hline Fibrinogen level (g/L) & & & $<1.0$ & & \\
\hline Diagnosis & 4 points or more & & 5 point & s or more & \\
\hline
\end{tabular}

These score was assessed using d-dimer if FDP was not measured. The cut off value of $\mathrm{d}$-dimer level were "moderate increase; $5.4-13.2$ $\mu \mathrm{g} / \mathrm{mL}$, strong increase; $\geq 13.2 \mu \mathrm{g} / \mathrm{mL}^{\prime \prime}$

JAAM: The revised Japanese Association for Acute Medicine

ISTH: The International Society on Thrombosis and Haemostasis

SIRS: systemic inflammatory response syndrome

Criteria for SIRS (systemic inflammatory response syndrome)

- Temperature: $>38^{\circ} \mathrm{C}$ or $<36{ }^{\circ} \mathrm{C}$

- Heart rate: $>90$ beats/min

- Respiratory rate: $>20$ breath $/ \mathrm{min}$ or $\mathrm{PaCO} 2<32$ Torr $(<4.3 \mathrm{kPa})$

-White cell blood counts: $>12,000 / \mathrm{mm} 3,<4,000$ cells $/ \mathrm{mm} 3$, or $10 \%$ immature (band) forms 


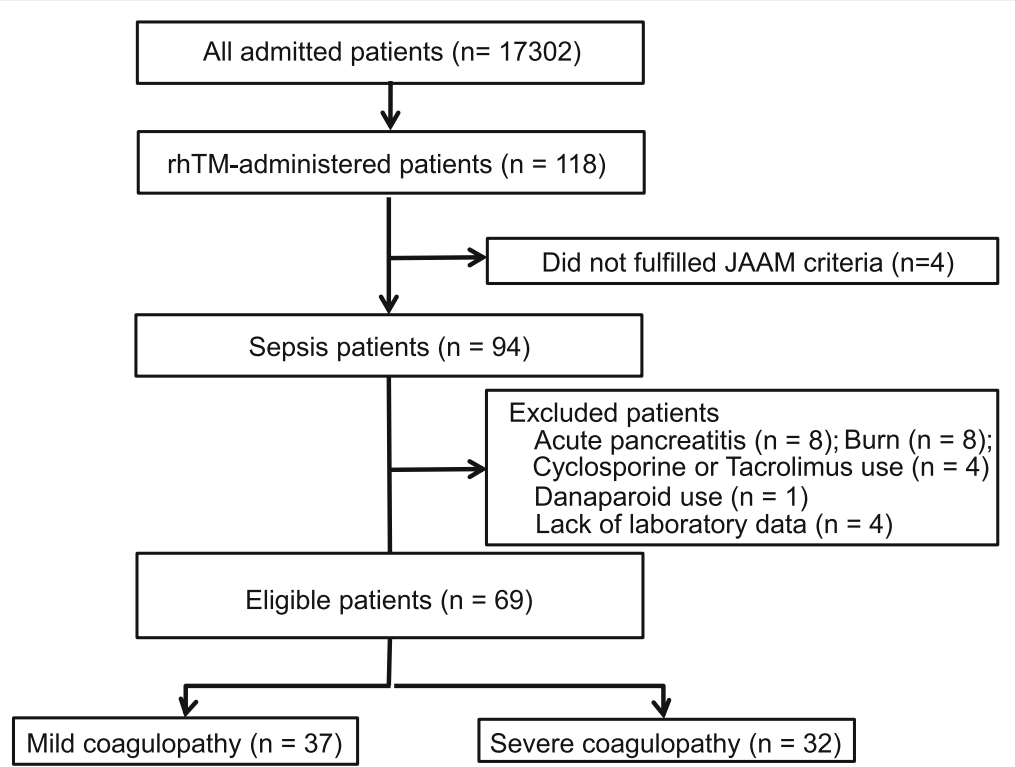

Fig. 1 Flow diagram of patient inclusion and exclusion criteria. rhTM, recombinant human soluble thrombomodulin. JAAM, Japanese Association for Acute Medicine

(APACHE II) score, sequential organ failure assessment (SOFA) score (Table 2) [21], presence of DIC as defined by the ISTH overt DIC criteria [22], mechanical ventilation, renal replacement therapy, vasopressor use, presence of cancer, prothrombin time (PT) ratio, antithrombin III (AT III) activity, D-dimer level, platelet count, fibrinogen level and lactate level. The SOFA score was recorded on days $1,3,5,7$ and 28 after administration of rhTM.

\section{Evaluation of clinical response}

Patients were assigned to either the severe coagulopathy group or the mild coagulopathy group. Severe coagulopathy was defined as diagnosed DIC by not only JAAM criteria (Score $\geq 4$ ) but also ISTH overt DIC criteria (Score $\geq 5)$. Mild coagulopathy was defined as fulfilled the JAAM criteria only (Table 1 ).
We evaluated about 90-day mortality and SOFA score at day 1, 3, 5, 7 and 28. An animal study has been reported that rhTM prevents endotoxin-induced lung injury [14]. Therefore SOFA score was also evaluated for the following components: respiratory, cardiovascular, hepatic, renal and coagulation. Moreover, changes over time in coagulation test results (D-dimer level, PT ratio and fibrinogen level) were assessed from day 1 to day 7 . PT and fibrinogen were measured by electric impedance methods (PT: Thrombocheck PT; Sysmex CO., LTD., fibrinogen: Coagpia ${ }^{\circ}$ Fbg; Sekisui medical CO., LTD.). FDP and D-dimer were measured by latex nephelometric immunoassay (Nanopia ${ }^{\circ}$ P-FDP; Sekisui medical CO., LTD., LIAS AUTO ${ }^{\circ}$ D-Dimer NEO; Sysmex CO., LTD.). AT III activity was measured by synthetic substrate method (Testzym ${ }^{\circ} \mathrm{S}$ AT III; Sekisui medical CO., LTD.).

Table 2 SOFA score [21]

\begin{tabular}{|c|c|c|c|c|}
\hline SOFA score & 1 & 2 & 3 & 4 \\
\hline $\begin{array}{l}\text { Respiratory } \\
\mathrm{PaO} 2 / \mathrm{FiO} 2, \mathrm{mmHg}\end{array}$ & $<400$ & $<300$ & $\begin{array}{l}<200 \text { (With respiratory } \\
\text { support) }\end{array}$ & $\begin{array}{l}<100 \text { (With respiratory } \\
\text { support) }\end{array}$ \\
\hline $\begin{array}{l}\text { Coagulation } \\
\text { Platelets } \times 103 / \mu l\end{array}$ & $<150$ & $<100$ & $<50$ & $<20$ \\
\hline $\begin{array}{l}\text { Hepatic } \\
\text { Bilirubin, mg/dl }\end{array}$ & $1.2-1.9$ & $2.0-5.9$ & $6.0-11.9$ & $>12.0$ \\
\hline $\begin{array}{l}\text { Cardiovascular } \\
\text { (Adrenergic agents dose is in } \mu \mathrm{g} / \mathrm{kg} / \\
\text { min) }\end{array}$ & $\begin{array}{l}\text { MAP }< \\
70 \mathrm{mmHg}\end{array}$ & $\begin{array}{l}\text { Dopamine } \leq 5 \\
\text { or dobutamine (any } \\
\text { dose) }\end{array}$ & $\begin{array}{l}\text { Dopamine }>5 \\
\text { or epinephrine } \leq 0.1 \\
\text { or norepinephrine } \leq 0.1\end{array}$ & $\begin{array}{l}\text { Dopamine }>15 \\
\text { or epinephrine }>0.1 \\
\text { or norepinephrine }>0.1\end{array}$ \\
\hline Central nervous system & $13-14$ & $10-12$ & $5-9$ & $<6$ \\
\hline $\begin{array}{l}\text { Renal } \\
\text { Creatinine, mg/dl or Urine output }\end{array}$ & $1.2-1.9$ & $2.0-3.4$ & $\begin{array}{l}3.5-4.9 \\
\text { Or }<500 \mathrm{ml} / \text { day }\end{array}$ & $\begin{array}{l}>5.0 \\
\text { Or } 200 \mathrm{ml} / \text { day }\end{array}$ \\
\hline
\end{tabular}




\section{Statistical analysis}

Data were expressed as group mean \pm standard deviation, or percentages. Continuous variables were compared between groups using the Student's $t$-test. Noncontinuous variables were compared between groups using the Mann-Whitney U test. Categorical variables were analyzed using the chi-squared test or Fisher's exact test. Log-rank analysis was used to evaluate 90-day mortality. Multivariate Cox regression analysis was used to assess the covariates that were associated with time to mortality. SOFA scores, Platelet count, D-dimer level, PT ratio and fibrinogen level between groups over time were analyzed by repeated measures analysis of variance and post hoc Dunnett's test. Independent predictive variables with a $P$ value of less than 0.05 were considered statistically significant. Statistical analyses were performed using JMP for Windows version 5.0.1 software (SAS Institute, Inc., U.S.).

\section{Results}

Baseline characteristics

Although 94 patients were diagnosed with sepsis and treated with rhTM during the study period, only 69 patients met the requirements of our study (Fig. 1). Thirty-seven patients were in the mild coagulopathy group and 32 patients were in the severe coagulopathy group. The characteristics of the study population are shown in Table 3. FDP levels were not measured in most of patients. ISTH overt DIC score, JAAM DIC score, Ddimer level and Platelet count were significant difference between mild coagulopathy group and severe coagulopathy group. These score was assessed using d-dimer if FDP was not measured. The cut off value of d-dimer level were "moderate increase; $5.4-13.2 \mu \mathrm{g} / \mathrm{mL}$, strong increase; $\geq 13.2 \mu \mathrm{g} / \mathrm{mL}$ ".

\section{Influence of treatment for mild or severe coagulopathy on mortality}

The Kaplan-Meier plot of survival function during the 90-day study period is given for both the mild coagulopathy group and the severe coagulopathy group in Fig. 2. There was trend toward lower 90-day mortality in the severe coagulopathy group than mild coagulopathy group $(P=0.029)$. We performed a Cox regression analysis to assessed four possible confounders related to

Table 3 Characteristics of patients

\begin{tabular}{|c|c|c|c|}
\hline & $\begin{array}{l}\text { Mild coagulopathy } \\
(n=37)\end{array}$ & $\begin{array}{l}\text { Severe coagulopathy } \\
(n=32)\end{array}$ & $P$ value \\
\hline Male, n (\%) & $25(67.6)$ & $23(71.9)$ & 0.796 \\
\hline Age (years) & 69 [38-94] & $72.5[33-91]$ & 0.110 \\
\hline Shock, n (\%) & $14(42.4)$ & $13(40.6)$ & 1.000 \\
\hline $\mathrm{AKI}, \mathrm{n}(\%)$ & $15(42.9)$ & $18(56.3)$ & 0.332 \\
\hline APACHE \| score & $26.6 \pm 8.1$ & $29.8 \pm 10.8$ & 0.229 \\
\hline SOFA score & $6.2 \pm 3.5$ & $7.5 \pm 2.5$ & 0.114 \\
\hline ISTH overt DIC score & $3.4 \pm 0.7$ & $5.3 \pm 0.6$ & $<0.001$ \\
\hline Mechanical ventilation, $\mathrm{n}(\%)$ & $31(88.6)$ & $30(93.8)$ & 0.675 \\
\hline Renal replacement therapy, n (\%) & $25(71.4)$ & $22(68.8)$ & 1.000 \\
\hline Vasopressor use, n (\%) & $24(68.6)$ & $24(75.0)$ & 0.598 \\
\hline Lactate $(\mathrm{mmol} / \mathrm{L})$ & $32.0 \pm 22.8$ & $38.3 \pm 21.5$ & 0.289 \\
\hline Time for normalize lactate level (h) & $94.8 \pm 142.6$ & $88.3 \pm 87.0$ & 0.854 \\
\hline Cancer, n (\%) & $6(16.7)$ & $5(15.6)$ & 1.000 \\
\hline rhTM dose (mg/kg) & $0.041 \pm 0.018$ & $0.048 \pm 0.023$ & 0.218 \\
\hline $\begin{array}{l}\text { Duration of rhTM } \\
\text { administration (days) }\end{array}$ & $5.4 \pm 1.8$ & $6.3 \pm 3.5$ & 0.181 \\
\hline \multicolumn{4}{|l|}{ Coagulation tests } \\
\hline Prothrombin time ratio & $1.34 \pm 0.28$ & $1.42 \pm 0.26$ & 0.212 \\
\hline Antithrombin III activity (\%) & $57.7 \pm 20.6$ & $54.5 \pm 21.8$ & 0.581 \\
\hline D-dimer $\left(10^{3} \mathrm{ng} / \mathrm{ml}\right)$ & $14.0 \pm 15.4$ & $40.0 \pm 65.0$ & $<0.001$ \\
\hline Platelet count $\left(10^{3} / \mu \mathrm{l}\right)$ & $10.0 \pm 10.1$ & $5.3 \pm 3.2$ & 0.004 \\
\hline Fibrinogen (mg/dl) & $420.3 \pm 216.7$ & $410.0 \pm 117.7$ & 0.813 \\
\hline
\end{tabular}

Collected data are when rhTM administration start

Data are presented as mean \pm standard deviation unless otherwise stated. DIC: disseminated intravascular coagulation, $A K I$ : acute kidney injury, APACHE II: acute physiologic and chronic health evaluation, SOFA: sequential organ failure assessment, ISTH: International Society on Thrombosis and Haemostasis, rhTM: recombinant human soluble thrombomodulin 


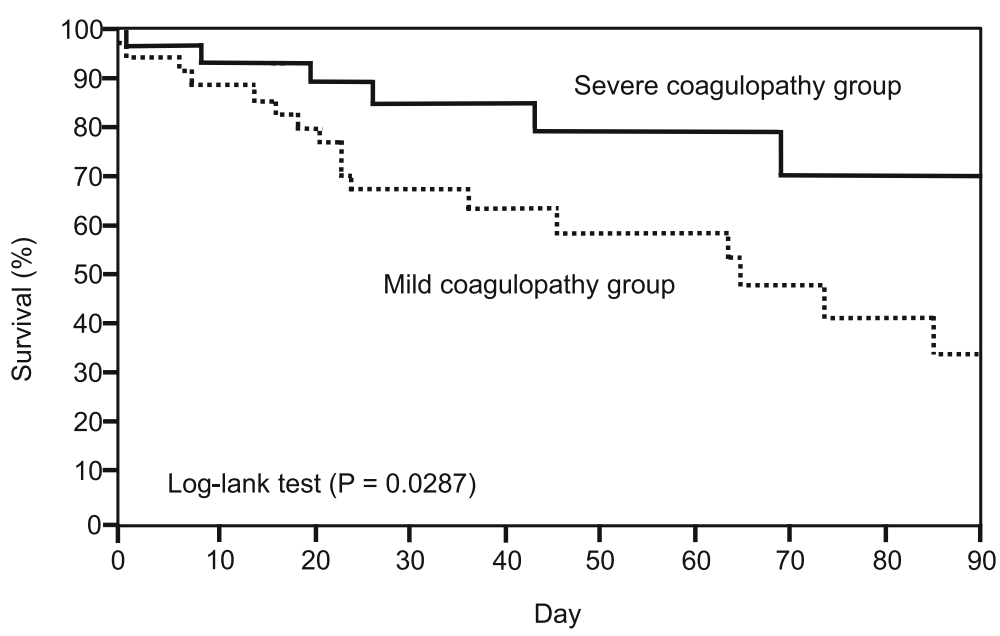

Fig. 2 Kaplan-Meier plot of survival at 90 daysThe solid line represents patients in the severe coagulopathy group, and the dotted line represents patients in the mild coagulopathy group. The mortality rate was significantly different between the two groups.

outcome: age, APACHE II score, SOFA score (day1) and severe coagulopathy. Consequently, severe coagulopathy influenced lower mortality $(p=0.015)$. (Table 4$)$.

\section{Sequential organ failure assessment score}

Although the SOFA score did not decrease in the mild coagulopathy group, it decreased significantly in the severe coagulopathy group at day7 and $28(P=0.001)$. There was trend toward lower SOFA scores in severe coagulopathy group than mild coagulopathy group on day $28(p=0.08)$ (Fig. 3). The respiratory component of the SOFA score significant decreased in severe coagulopathy group ( $p=0.029)$ (Table 5).

\section{Coagulation tests}

Prothrombin time ratio and D-dimer were improved in the severe coagulopathy group significantly compared with baseline. Although D-dimer level was higher in the severe coagulopathy group than mild coagulopathy group at day 1, D-dimer was not different between two groups.

Platelet count improved in both groups (not significant). Platelet count, Prothrombin time ratio, D-dimer and fibrinogen levels were not significantly different at day 7 between the groups. (Fig. 4).

Table 4 Cox regression analysis

\begin{tabular}{llll}
\hline & Risk ratio & $95 \% \mathrm{Cl}$ & $P$ value \\
\hline Age & 0.985 & $0.950-1.024$ & 0.422 \\
APACHE II score & 0.996 & $0.934-1.060$ & 0.909 \\
SOFA score (day 1) & 1.171 & $0.985-1.411$ & 0.074 \\
Severe coagulopathy & 0.554 & $0.314-0.897$ & 0.015 \\
\hline
\end{tabular}

$\mathrm{Cl}$ : confidence intervals, SOFA: sequential organ failure assessment, APACHE: acute physiologic and chronic health evaluation

\section{Discussion}

Although several trials have shown that rhTM reduced mortality in septic patients with DIC [13, 14, 17], the timing of treatment initiation was unclear. The present study represents the first attempt to evaluate efficacy of rhTM in septic patients with different degree of coagulopathy. This study suggested that treatment with rhTM in septic patients with severe coagulopathy improves mortality compared with those without severe coagulopathy.

The present study included 69 patients with sepsis. There was no difference in baseline characteristics except coagulation tests between severe coagulopathy group and mild coagulopathy group. Platelet count was significantly lower and D-dimer level was significantly higher in the severe coagulopathy group than mild coagulopathy group. The sensitivity of a low fibrinogen level for the diagnosis of DIC according to ISTH criteria was $28 \%$ and hypofibrinogenemia has been detected in only severe cases of DIC [8]. Fibrinogen levels were normal in most of patients in the present study. Therefore, fibrinogen levels showed no significant differences between the two groups. PT ratio was improved significantly in the severe coagulopathy group at day 7 . There was significant reduction of SOFA score in severe coagulopathy group within 7 days compared with baseline. Furthermore, at day 7 and 28, the score was trends in lower of the severe coagulopathy group, as compared with mild coagulopathy group. On the other hand, there was no significant reduction of SOFA score in the mild coagulopathy group compared with baseline.

Severe coagulopathy is associated with high mortality in patients with sepsis. Patients with severe coagulopathy had higher mortality than those with mild coagulopathy $[6,23]$. The phase II study shown that rhTM trend 


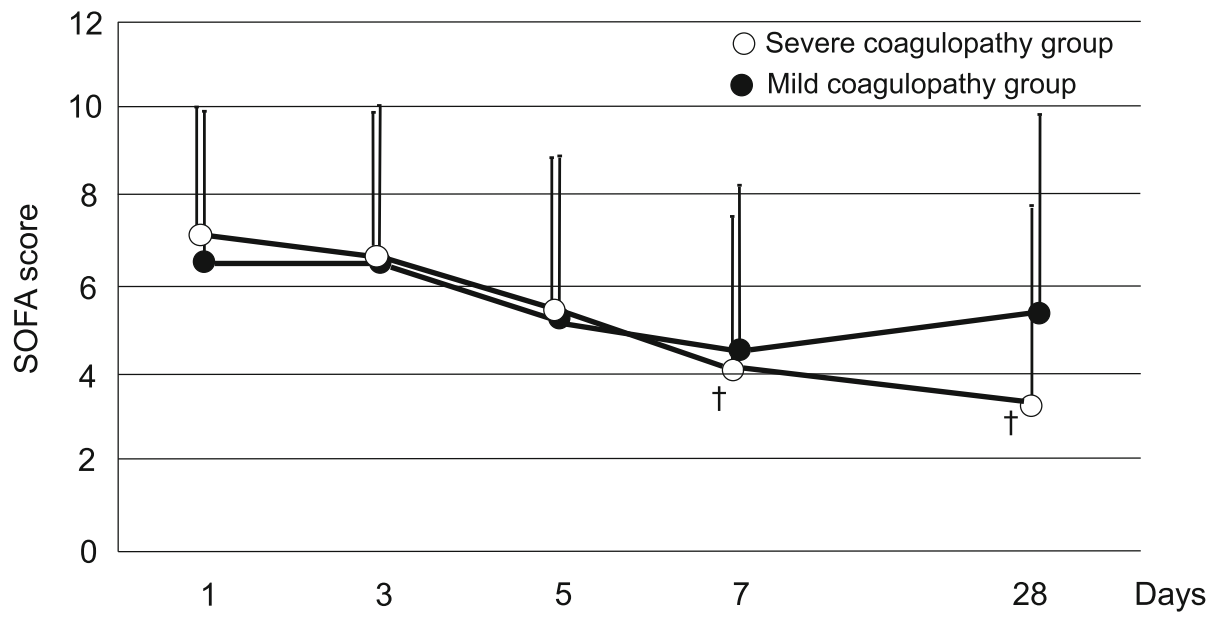

Fig. 3 Serial changes in the sequential organ failure assessment (SOFA) score in the severe coagulopathy group and in the mild coagulopathy groupOpen circle: Severe coagulopathy group. Filled circle: Mild coagulopathy group.Data are expressed as means \pm standard deviation. ${ }^{\dagger}$ Significant difference compared with day 1. There was trend toward lower SOFA scores in severe coagulopathy group than mild coagulopathy group on day $28(p=0.08)$.

toward to improve mortality compared with placebo in patients with sepsis [24]. The majority of patients included in the study were not severe coagulopathy state (ISTH DIC score <5). It was considered in the study that rhTM may be more beneficial for subjects with greater coagulation abnormality. Multicenter retrospective study has shown that rhTM improved mortality significantly [16]. Yoshimura et al. reported that rhTM improves mortality in high risk septic patients (APACHEII 24-29). On the other hand, rhTM did not improve mortality in moderate risk of septic patients (APACHE II score $<24$ ) [25]. Moreover ISTH score was significantly higher in high risk and very high risk of septic patients compared with moderate risk of septic patients. In addition, the patients included in this study were high risk of septic patients (APACHE II score; $27.1 \pm 8.1$ and $29.4 \pm 11.0$ ).

Generally, it is difficult to determine the survival benefit of a particular lifesaving therapy in a set of patients with a low risk of mortality. This may be one of the reasons why thTM administration does not reduce the mortality risk in patients who are not at high risk in the first place. On the other hand, these results are congruent with recent pathophysiological findings concerning

Table 5 The components of the SOFA score at day 7

\begin{tabular}{llll}
\hline & $\begin{array}{l}\text { Mild coagulopathy } \\
(n=37)\end{array}$ & $\begin{array}{l}\text { Severe coagulopathy } \\
(n=32)\end{array}$ & $P$ value \\
\hline Respiratory & $0.93 \pm 0.18$ & $0.44 \pm 0.18$ & 0.029 \\
Cardiovascular & $0.83 \pm 0.25$ & $1.08 \pm 0.27$ & 0.438 \\
Hepatic & $1.50 \pm 0.29$ & $1.43 \pm 0.30$ & 0.843 \\
Renal & $1.12 \pm 0.25$ & $0.78 \pm 0.26$ & 0.673 \\
Coagulation & $1.54 \pm 0.19$ & $1.23 \pm 0.20$ & 0.253 \\
\hline
\end{tabular}

Data are presented as mean \pm standard error unless otherwise stated the innate immune response. Under certain circumstances, thrombosis is considered to play a major physiological role, which is specifically named immunothrombosis, in immune defense [26]. However, aberrant of uncontrolled activation of immunothrombosis is likely to constitute a key event in the development of thrombotic disorders [27]. In patients in the mild coagulopathy state, rhTM could have inhibited host-defensive thrombosis, which suppress to capture and ensnare pathogens circulating in the blood, and therefore failed to improve mortality. In contrast, immunothrombosis could have been aberrantly activated and proved detrimental to the host in patients in the severe coagulopathy state, which may have improved mortality. SOFA score was trends in lower of the severe coagulopathy group, as compared with mild coagulopathy group. It is considered that rhTM may improve organ dysfunction by improving severe coagulopathy. Furthermore, respiratory component of the SOFA score was significant reduction in the severe coagulopathy group than mild coagulopathy group in the present study.

Several studies have shown that rhTM improves coagulopathy in disseminated intravascular coagulation $[28,29]$.

Yamakawa et al. showed that rhTM improves coagulopathy, mortality and SOFA score compared with control group [17]. It was discussed in the study that suppressing the hypercoagulative state by rhTM administration may potentially prevent the progression to multiple organ failure. rhTM has the effect of directly combining with thrombin. Thrombin - rhTM complex activates protein $\mathrm{C}$. Therefore the anticoagulative effect of rhTM depends on the amount of thrombin available. The subgroup analysis of PROWESS trial has shown that activated protein $\mathrm{C}$ improves respiratory dysfunction in patients with sepsis [30]. Moreover, Ogawa et al., 


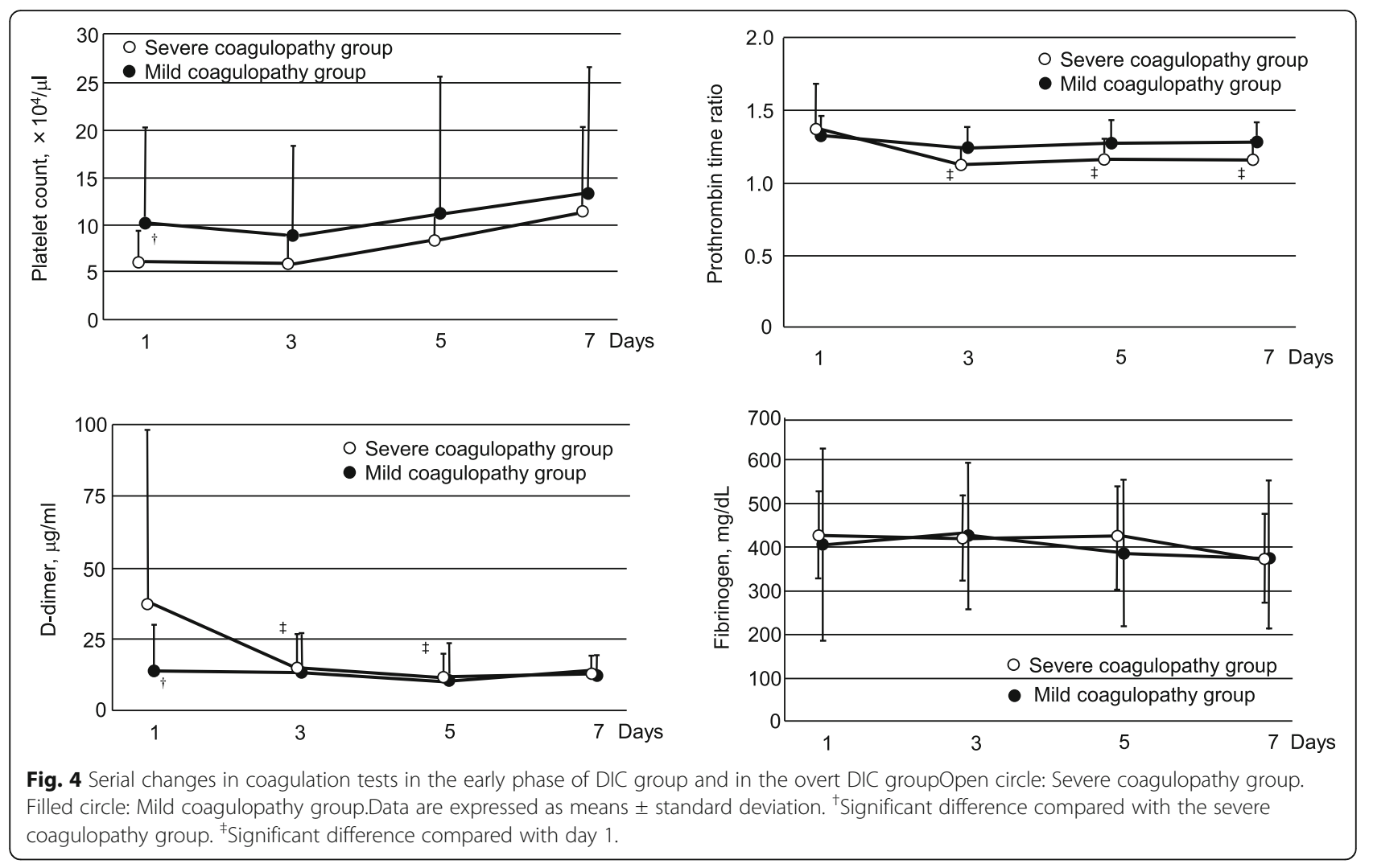

reported the respiratory component of the SOFA score reduced significantly in patients with DIC who treated by rhTM compared with placebo [31]. The results of this study indicate that respiratory component of the SOFA score was more reduced in the severe coagulopathy group than the mild coagulopathy group. rhTM was considered to improve respiratory dysfunction by more activating protein $\mathrm{C}$ in severe coagulopathy state than mild coagulopathy state. Therefore, administrating rhTM might more improve not only coagulopathy but also respiratory dysfunction in patients with severe coagulopathy compared with those without rhTM. We considered that there might be relation among SOFA score and mortality, SOFA score was not selected as covariate for mortality in current study. We considered reason of above was because of small sample size.

We acknowledge several limitations of our observational study design. First, this study was retrospective small scale trial. Second, this study is not a randomized placebo controlled trial. Multiple unmeasured variables might account for the outcome differences observed in this study. Third, this study was carried out in a single institution. Further multicenter, prospective randomized trials are needed to thoroughly evaluate the effects of rhTM on the treatment of septic patients with coagulopathy.

\section{Conclusion}

In conclusion, we found that rhTM administration may reduce mortality by improving organ dysfunction especially for respiratory in septic patients with severe coagulopathy. The present study represents the first attempt to evaluate efficacy of rhTM in septic patients with different degree of coagulopathy. Further clinical investigations are necessary to evaluate the effect of rhTM in several degree of coagulopathy.

\section{Abbreviations}

AKI: Acute kidney injury; APACHE II: Acute Physiologic and Chronic Health Evaluation II; AT III: Antithrombin III; DIC: Disseminated intravascular coagulation; ICU: Intensive care unit; ISTH: Subcommittee of the International Society on Thrombosis and Haemostasis; JAAM: Japanese Association for Acute Medicine; PT: Prothrombin time; rhTM: Recombinant human soluble thrombomodulin; SOFA: Sequential Organ Failure Assessment; SSC: Surviving sepsis campaign

\section{Availability of data and materials}

Please contact author for data requests.

\section{Authors' contributions}

TK and KM contributed to the study conception and design, collected and assembled the study data, contributed to the writing and revising of the manuscript, and provided final approval of the manuscript. TK performed the statistical analysis. All authors read and approved the final manuscript.

\section{Ethics approval and consent to participate}

The study protocol was reviewed and approved by an institutional review board. Informed consent was not required because blood samples were taken as part of the routine patient care for clinical laboratory testing, but the highest standard of privacy policy was applied. 


\section{Competing interests}

The authors declare that they have no competing interests.

\section{Publisher's Note}

Springer Nature remains neutral with regard to jurisdictional claims in published maps and institutional affiliations.

\section{Author details}

'Departments of Pharmacy, Aichi Medical University, 1 -1 Yazakokarimata, Nagakute, Aichi 480-1195, Japan. 'Laboratory of Clinical Pharmacodynamics, Aichi Gakuin University School of Pharmacy, Nagakute, Japan.

Received: 16 January 2018 Accepted: 6 May 2018

Published online: 24 August 2018

\section{References}

1. Martin GS, Mannino DM, Eaton S, Moss M. The epidemiology of sepsis in the United States from 1979 through 2000. N Engl J Med. 2003;348:1546-54

2. Levy MM, Dellinger RP, Townsend SR, Linde-Zwirble WT, Marshall JC, Bion J, et al. The surviving Sepsis campaign: results of an international guidelinebased performance improvement program targeting severe sepsis. Intensive Care Med. 2010;36:222-31.

3. Miller RR 3rd, Dong L, Nelson NC, Brown SM, Kuttler KG, Probst DR, et al. Multicenter implementation of a severe sepsis and septic shock treatment bundle. Am J Respir Crit Care Med. 2013;188:77-82.

4. Ferrer R, Artigas A, Levy MM, Blanco J, González-Díaz G, Garnacho-Montero J, et al. Improvement in process of care and outcome after a multicenter severe sepsis educational program in Spain. JAMA. 2008;299:2294-303.

5. Zhang L, Zhu G, Han L, Fu P. Early goal-directed therapy in the management of severe sepsis or septic shock in adults: a meta-analysis of randomized controlled trials. BMC Med. 2015:13:71.

6. Bakhtiari K, Meijers JC, de Jonge $E$, Levi M. Prospective validation of the International Society of Thrombosis and Haemostasis scoring system for disseminated intravascular coagulation. Crit Care Med. 2004;32:2416-21.

7. Zeerleder S, Hack CE, Wuillemin WA. Disseminated intravascular coagulation in sepsis. Chest. 2005;128:2864-75.

8. Levi M, Toh $\mathrm{CH}$, Thachil J, Watson HG. Guidelines for the diagnosis and management of disseminated intravascular coagulation. Br J Haematol. 2009;145:24-33.

9. Wada H, Wakita Y, Nakase T, Shimura M, Hiyoyama K, Nagaya S, et al. Outcome of disseminated intravascular coagulation in relation to the score when treatment was begun. Mie DIC Study Group Thromb Haemost. 1995;74:848-52.

10. Dhainaut JF, Yan SB, Joyce DE, Pettilä V, Basson B, Brandt JT, et al. Treatment effects of drotrecogin alfa (activated) in patients with severe sepsis with or without overt disseminated intravascular coagulation. J Thromb Haemost. 2004:2:1924-33.

11. Gando S, Iba T, Eguchi Y, Ohtomo Y, Okamoto K, Koseki K, Mayumi T, Murata A, Ikeda T, Ishikura H, Ueyama M, Ogura H, Kushimoto S, Saitoh D, Endo S. Shimazaki S; a multicenter, prospective validation of disseminated intravascular coagulation diagnostic criteria for critically ill patients: comparing current criteria. Crit Care Med. 2006;34:625-31.

12. Saito H, Maruyama I, Shimazaki S, Yamamoto Y, Aikawa N, Ohno R, et al. Efficacy and safety of recombinant human soluble thrombomodulin (ART123 ) in disseminated intravascular coagulation: results of a phase III, randomized, double-blind clinical trial. J Thromb Haemost. 2007;5:31-41.

13. Iba T, Nakarai E, Takayama T, Nakajima K, Sasaoka T, Ohno Y. Combination effect of antithrombin and recombinant human soluble thrombomodulin in a lipopolysaccharide induced rat sepsis model. Crit Care. 2009:13:R203.

14. Uchiba M, Okajima K, Murakami K, Johno M, Okabe H, Takatsuki K. Recombinant thrombomodulin prevents endotoxin-induced lung injury in rats by inhibiting leukocyte activation. Am J Phys. 1996;271:L470-5.

15. Yamakawa K, Aihara M, Ogura H, Yuhara H, Hamasaki T, Shimazu T. Recombinant human soluble thrombomodulin in severe sepsis: a systematic review and meta-analysis. J Thromb Haemost. 2015;13:508-19.

16. Hayakawa M, Yamakawa K, Saito S, Uchino S, Kudo D, lizuka Y, et al. Recombinant human soluble thrombomodulin and mortality in sepsisinduced disseminated intravascular coagulation. A multicentre retrospective study. Thromb Haemost. 2016;115:1157-66.

17. Yamakawa K, Fujimi S, Mohri T, Matsuda H, Nakamori $Y$, Hirose T, et al. Treatment effects of recombinant human soluble thrombomodulin in patients with severe sepsis: a historical control study. Crit Care. 2011:15:R123.

18. Seymour CW, Liu VX, Iwashyna TJ, Brunkhorst FM, Rea TD, Scherag A, et al. Assessment of clinical criteria for Sepsis: for the third international consensus definitions for Sepsis and septic shock (Sepsis-3). JAMA. 2016;315:762-74.

19. Dellinger RP, Levy MM, Rhodes A, Annane D, Gerlach H, Opal SM, et al. Surviving Sepsis campaign: international guidelines for Management of Severe Sepsis and Septic Shock, 2012. Intensive Care Med. 2013;39:165-228.

20. Mehta RL, Kellum JA, Shah SV, Molitoris BA, Ronco C, Warnock DG, et al. Acute kidney injury network: report of an initiative to improve outcomes in acute kidney injury. Crit Care. 2007;11:R31.

21. Vincent JL, Moreno R, Takala J, Willatts S, De Mendonça A, Bruining H, et al. The SOFA (Sepsis-related organ failure assessment) score to describe organ dysfunction/failure. On behalf of the working group on Sepsis-related problems of the European Society of Intensive Care Medicine. Intensive Care Med. 1996;22:707-10.

22. Taylor FB Jr, Toh $\mathrm{CH}$, Hoots WK, Wada H, Levi M. Towards definition, clinical and laboratory criteria, and a scoring system for disseminated intravascular coagulation. Thromb Haemost. 2001;86:1327-30.

23. Gando S, Iba T, Eguchi Y, Ohtomo Y, Okamoto K, Koseki K, et al. A multicenter, prospective validation of disseminated intravascular coagulation diagnostic criteria for critically ill patients: comparing current criteria. Crit Care Med. 2006:34:625-31.

24. Vincent JL, Ramesh MK, Ernest D, LaRosa SP, Pachl J, Aikawa N, et al. A randomized, double-blind, placebo-controlled, phase $2 \mathrm{~b}$ study to evaluate the safety and efficacy of recombinant human soluble thrombomodulin, ART-123, in patients with sepsis and suspected disseminated intravascular coagulation. Crit Care Med. 2013;41:2069-79.

25. Yoshimura J, Yamakawa K, Ogura H, Umemura Y, Takahashi H, Morikawa M, et al. Benefit profile of recombinant human soluble thrombomodulin in sepsis-induced disseminated intravascular coagulation: a multicenter propensity score analysis. Crit Care. 2015;19:78.

26. Engelmann B, Massberg S. Thrombosis as an intravascular effector of innate immunity. Nat Rev Immunol. 2013:13:34-45.

27. Esmon CT. The interactions between inflammation and coagulation. $\mathrm{Br}$ J Haematol. 2005:131:417-30.

28. Yasuda N, Goto K, Ohchi Y, Abe T, Koga H, Kitano T, et al. The efficacy and safety of antithrombin and recombinant human thrombomodulin combination therapy in patients with severe sepsis and disseminated intravascular coagulation. J Crit Care. 2016;36:29-34.

29. Hashimoto D, Chikamoto A, Miyanari N, Ohara C, Kuramoto M, Horino K, et al. Recombinant soluble thrombomodulin for postoperative disseminated intravascular coagulation. J Surg Res. 2015:197:405-11.

30. Vincent $J$, Angus DC, Artigas A, Kalil A, Basson BR, Jamal HH, et al. Effects of drotrecogin alfa (activated) on organ dysfunction in the PROWESS trial. Crit Care Med. 2003;31:834-40

31. Ogawa Y, Yamakawa K, Ogura H, Kiguchi T, Mohri T, Nakamori $Y$, et al. Recombinant human soluble thrombomodulin improves mortality and respiratory dysfunction in patients with severe sepsis. J Trauma. 2012:72:1150-7.

\section{Ready to submit your research? Choose BMC and benefit from:}

- fast, convenient online submission

- thorough peer review by experienced researchers in your field

- rapid publication on acceptance

- support for research data, including large and complex data types

- gold Open Access which fosters wider collaboration and increased citations

- maximum visibility for your research: over $100 \mathrm{M}$ website views per year

At BMC, research is always in progress.

Learn more biomedcentral.com/submissions 